\title{
High Performance Polyamide 6 Fibers Using Polycarbonate Based Thermoplastic Polyurethane Thin Film Coatings- a Novel Method
}

\author{
By Baiju JoHN, ${ }^{1}$ Ken KOJIO, ${ }^{2}$ and Mutsuhisa FURUKAWA ${ }^{1, *}$
}

Polycarbonate based thermoplastic polyurethanes (CPU2) were prepared and coated onto polyamide 6 (PA 6) fibers. The CPU2 thin film coatings were prepared by dipping the PA 6 fibers into a viscous CPU2 adduct and cured at $100{ }^{\circ} \mathrm{C}$ for $12 \mathrm{~h}$. Both the tensile strength and the elongation at break of the CPU2 thin film coated PA 6 fibers (CPU2-PA6) increased although both the magnitudes of CPU2 are much lower than for the original PA 6 fibers. FE-SEM observation revealed that there existed an interface interaction region of $10 \mu \mathrm{m}$ at the interface of PA 6 fiber and the CPU2 thin film coating. Generally speaking, it is considered that the break of PA 6 fibers is due to the formation of the micro-cracks on the fiber surface when it is under a tensile load. The coating of CPU2 onto the PA 6 fibers reduced the formation of micro-cracks during the elongation process, resulted in the improvement of the mechanical properties. Also, the CPU2-PA6 fibers when exposed to weathering tests to check the weathering resistance, showed an increase in the tensile strength for $0-50 \mathrm{~h}$ of exposure. This was due to the UV light induced crystalline transformation, i.e., from the $\alpha$ crystalline phase to the $\gamma$ crystalline phase. The CPU2-PA6 fibers almost retained the strength even after $200 \mathrm{~h}$ of exposure in a weatherometer. The crystalline transformations due to the UV irradiations have not been reported yet. Also, the CPU2 showed good adhesion property with the PA 6 films. The blending with various polymers or composites is generally employed for the performance enhancement of PA 6 fibers. On the contrary, the method employed in this study improved the performance of PA 6 fibers without changing its inherent morphological properties.

KEY WORDS: Polyamide 6 Fiber / Polyurethane Thin Film / Coating / Micro-cracks / Interface Interaction / Plastic-type Break /

Metallic-type Break / Weathering Tests /

Polyamide fibers (PAs) are used for a wide variety of applications. They include the textile industry, engineering applications, biomedical and marine applications. The properties of PAs are the high melting point, good mechanical strength, good resistance to hydrocarbons, and the ease of fabrication and processing. ${ }^{1-3}$ However, the polyamide 6 (PA 6) fibers are prone to break under the mechanical stress due to the formation of micro-cracks on the surface. While, the polyurethanes are widely used in the coatings, adhesives, sealants, foams, elastomers and so on. Thermoplastic polyurethane elastomers are well known for their abrasion resistance, flexibility and high cohesive strength. ${ }^{4-6}$ They are synthesized from the polymer glycol, diisocyanate and a chain extender. The final structure of polyurethane consists of a soft segment formed from the polymer glycol and a hard segment from the diisocyanate and the chain extender. The soft segment can be classified as an ether or ester series, including the carbonate ones. ${ }^{7,8}$ Studies have been reported with polyamide in the thermoplastic elastomers or rubbers as blends. ${ }^{9}$ The PA 6/acrylonitrile-butadiene-styrene blends obtained with an imidized acrylic polymer as a compatabilizer revealed supertough properties over a wide range of component proportions. ${ }^{10}$ The miscibility of PA 6/thermoplastic polyurethane blends revealed that the multiphase systems obtained have an elastomeric polymeric phase which is finely displaced into the polyamide matrix. ${ }^{11}$ The non-isothermal crystallization temperature of the polyamide phase was lowered in the case of PA 6/polyurethane blends mixed by the copolyurethaneamides. ${ }^{12}$ The fibers made out of polypropylene and polyamide composites showed variation in the mechanical properties with the processing temperatures. ${ }^{13}$ The improvement of mechanical properties of PA 6 fibers coated with the polyurethane thin film coating has not been reported yet. The polycarbonate based thermoplastic polyurethanes (CPUs) are becoming popular these days due the excellent resistance to heat, hydrolysis and ultraviolet radiation in comparison with the ether series. ${ }^{14}$

In this study, the polycarbonate based thermoplastic polyurethane (CPU2) adduct was prepared and thin film coated onto the PA 6 fibers, the performance of the same was characterized by various methods.

\section{EXPERIMENTAL}

\section{Materials}

Figure 1 shows the raw materials used for the study. The polyol; poly(hexamethylene carbonate) glycol (PCG) of number average molecular weight $\left(M_{\mathrm{n}}\right)$ of 1076 and the diisocyanate; 4,4'-diphenylmethane diisocyanate (MDI) were supplied

\footnotetext{
${ }^{1}$ Division of Materials Science, Graduate School of Science and Technology, Nagasaki University, 1-14 Bunkyo-machi, Nagasaki 852-8521, Japan ${ }^{2}$ Department of Materials Science and Engineering, Faculty of Engineering, Nagasaki University, 1-14 Bunkyo-machi, Nagasaki 852-8521, Japan *To whom correspondence should be addressed (Tel/Fax: 095-819-2651, E-mail: furukawa@nagasaki-u.ac.jp).
} 


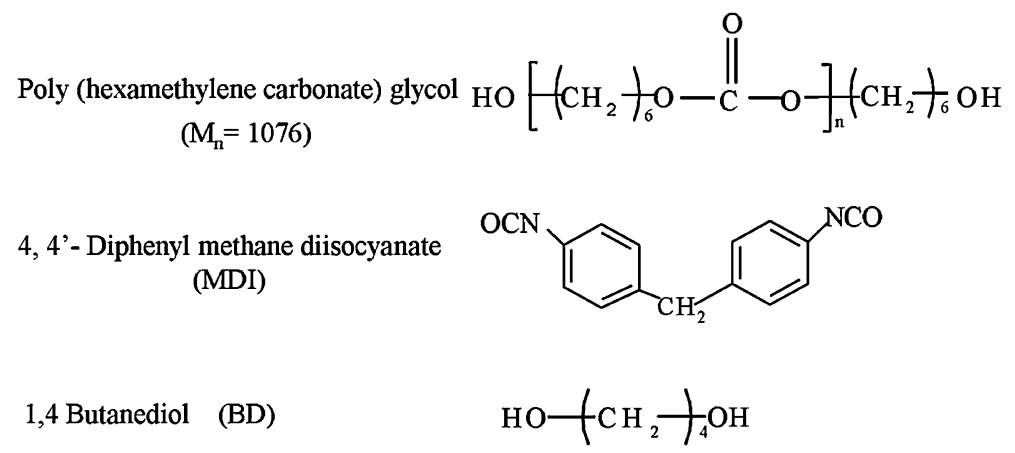

Figure 1. Raw materials used for the preparation of polycarbonate based polyurethane (CPU2) adduct.

by Asahi Kasei Chemicals Co., Ltd., Japan and Nippon Polyurethane Industry, Co., Ltd., Japan, respectively. The chain extender, 1,4-butanediol (BD) was purchased from Wako Chemical, Co., Ltd., Japan. The PCG was dried by passing the nitrogen gas under reduced pressure at $100^{\circ} \mathrm{C}$ and the BD was distilled prior to the use in polymerization. The PA 6 monofilament $(\phi=520 \mu \mathrm{m})$ purchased from Toray Co., Ltd., Japan was used for this study.

\section{Preparation of the Thermoplastic Polycarbonate Poly-} urethane (CPU2) Adduct and CPU2-PA6 Fibers

One shot method of preparation was adopted for the preparation of CPU2 adduct. The CPU2 was prepared for the ratio, $\mathrm{K}$, of $[\mathrm{NCO}] /[\mathrm{OH}]_{\mathrm{PCG}}$ which equals to 2.05 and for the $\mathrm{NCO}$ index, $[\mathrm{NCO}] /[\mathrm{OH}]_{\mathrm{PCG}+\mathrm{BD}}$ which equals to 1.05 . The PCG was mixed with $\mathrm{BD}$ at $100^{\circ} \mathrm{C}$ and agitated for $3 \mathrm{~min}$ under a nitrogen atmosphere. Then MDI was added to it and agitated for $30 \mathrm{~s}$ and the whole mixture was vacuum-agitated for $1 \mathrm{~min}$. The PA 6 monofilament fibers were cleaned using distilled water in an ultrasonic water bath for $15 \mathrm{~min}$ and dried at room temperature. The polyurethane adduct was dip-coated on these fibers for $36 \mathrm{~s}$ and cured at $100^{\circ} \mathrm{C}$ for $12 \mathrm{~h}$. Also, the PA 6 fiber sample was annealed at $100^{\circ} \mathrm{C}$ to take into account the effect of annealing due to the curing of polycarbonate based polyurethane (CPU2) at $100^{\circ} \mathrm{C}$.

\section{Preparation of CPU2-PA6 Films for Adhesion Studies}

The PA 6 fibers used for the study were minced into small pellets. These pellets were melted on a hot plate at around $230^{\circ} \mathrm{C}$. The melted pellets were then pressed with another glass plate and the system was gradually cooled. The obtained film had a thickness of $200 \mu \mathrm{m}$ and the dimension of the specimen was $5 \mathrm{~mm} \times 50 \mathrm{~mm}$. The film was then dipped in the CPU2 adduct and cured at $100{ }^{\circ} \mathrm{C}$ for $12 \mathrm{~h}$. For the single lap shear test, the area of lap was $5 \mathrm{~mm} \times 5 \mathrm{~mm}$ and for the $\mathrm{T}$-peel test, the contact area was $30 \mathrm{~mm} \times 5 \mathrm{~mm}$. In the case of peeling test, the PA 6 film was dipped in CPU2 adduct and the coated film was peeled against the PA 6 film. Thickness, $t$, of the CPU2-PA6 fiber was calculated by equation.

$$
\mathrm{t}=\left[\left(\phi_{\text {coated fiber }}-\phi_{\text {uncoated fiber }}\right) / 2\right]
$$

where $\phi_{\text {coated fiber }}$ and $\phi_{\text {uncoated fiber }}$ are the diameters of the
CPU2-PA6 and uncoated PA 6 fiber, respectively.

The samples used in this study were designated as PA 6, Ann PA, CPU2, CPU2-PA6. They were the polyamide 6 fiber, polyamide 6 fiber annealed at $100^{\circ} \mathrm{C}, \mathrm{CPU}$ with $\mathrm{K}$ value of 2.05 and CPU2 thin film coated polyamide 6 fiber with $\mathrm{K}$ value of 2.05 , respectively.

\section{Characterization of CPU2-PA6 Fibers}

The POM images were obtained with a Nikon OPTIPHTO2POL polarized optical microscope equipped with a Linkam TH500PM heating stage (Germany). The field emission SEM (FE-SEM) images were taken with the JEOL JSM-7500 scanning electron microscope (Japan). It was operated at $5 \mathrm{kV}$ and the samples were gold sputtered prior to SEM examination.

FT-IR studies were conducted to analyze the structural transformations that occur in the PA 6 fiber due to the CPU2 coating. The FT-IR cross sectional scanning of the fiber was conducted through a microscope in the ATR mode at a range from 400-4000 $\mathrm{cm}^{-1}$ (UMA-600 FT-IR microscope, Bio-Rad laboratories Inc. FTS 3000 type, USA). This was taken with an inbuilt camera attached to it and the images were viewed on the computer screen. All spectra were collected from the 32 scans and at a resolution of $4 \mathrm{~cm}^{-1}$. The position for the scanning was adjusted by viewing through the microscope.

DSC measurements were performed to determine the thermal behavior of PA 6 fibers and CPU2-PA6 fibers. The DSC curves were obtained with a Rigaku DSC 8230 differential scanning calorimeter (Japan) from -150 to $250^{\circ} \mathrm{C}$ at a heating rate of $10^{\circ} \mathrm{C} \mathrm{min}^{-1}$ under a nitrogen atmosphere. The samples prepared were cooled to approximately $-150^{\circ} \mathrm{C}$ at a cooling rate of $6-8{ }^{\circ} \mathrm{C} \mathrm{min}^{-1}$, and then the measurements were started.

The temperature dependence of the dynamic viscoelastic properties was measured with a DMS 6100 dynamic viscoelastic tester (Seiko Instruments, Co., Ltd. Japan). The measurements were performed from -150 to $250{ }^{\circ} \mathrm{C}$ at a heating rate of $2{ }^{\circ} \mathrm{C} \mathrm{min}^{-1}$ under a nitrogen atmosphere. The length of the sample used was $5 \mathrm{~mm}$. The imposed strain and frequency were set at $2 \%$ and $10 \mathrm{~Hz}$, respectively.

WAXD profiles were obtained with a $2 \theta$ scan mode with a RINT2200 (Rigaku Co., Ltd., Japan). The voltage and current of $\mathrm{Cu} \mathrm{K} \alpha \mathrm{X}$-ray source were $30 \mathrm{kV}$ and $16 \mathrm{~mA}$, respectively. 


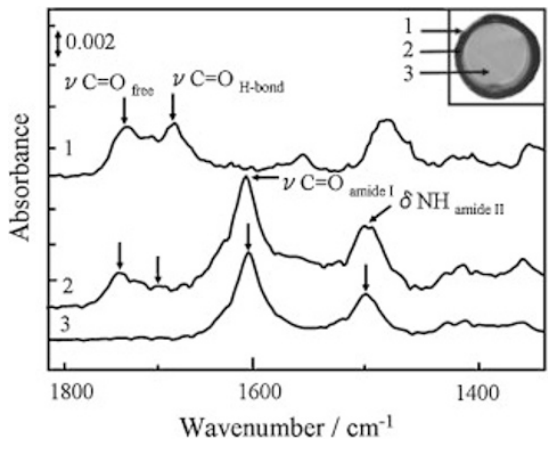

(a)

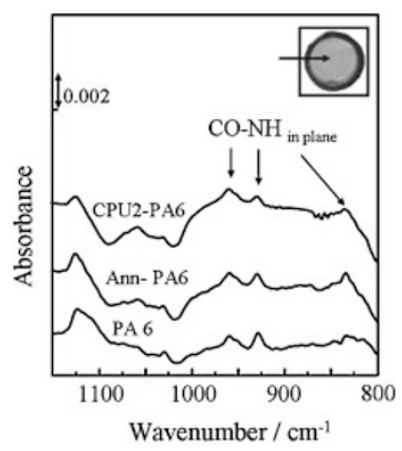

(b)

Figure 2. FT-IR spectra showing the structural changes inside the CPU-PA6 fiber.

The tensile tests were performed with an Instron type tensile tester (Tensilon, U-440 model, Orientec Co., Ltd., Japan) at $20{ }^{\circ} \mathrm{C}$. The initial length and the elongation rate were set at $30 \mathrm{~mm}$ and $10 \mathrm{~mm} \mathrm{~min}^{-1}$, respectively.

Weathering studies were conducted using a weatherometer (SC700-FA, Sugasu Machine Company Ltd., Japan) and the source used was a Xe arc lamp (continuous irradiation of $180 \mathrm{~W} / \mathrm{m}^{2}$ and wavelength of $200-300 \mathrm{~nm}$ ). The raining was for $18 \mathrm{~min}$ and the interval between each raining was $120 \mathrm{~min}$. The black panel temperature was $65^{\circ} \mathrm{C}$ during irradiation and $45^{\circ} \mathrm{C}$ during raining. The total exposure time was $200 \mathrm{~h}$ and the samples were retrieved after every $50 \mathrm{~h}$. The length of the fiber samples loaded on the experimental frame for exposure was $40 \mathrm{~mm}$.

\section{RESULTS AND DISCUSSION}

Table I shows the properties of the samples studied and the average thickness of CPU2 thin film coating on the PA 6 fiber was $40 \mu \mathrm{m}$ with a variation of $\pm 5 \mu \mathrm{m}$. The density of the Ann PA was the same as that of the PA 6 and the coating weight fraction of the CPU2 thin film on CPU2-PA6 fiber was nearly $20 \%$.

\section{Morphological Features}

In CPU2-PA6 fiber, an interface interaction region was formed at the interface of CPU2 thin film coating and the PA 6 fiber. The interface interaction region with a width of $10 \mu \mathrm{m}$ is clearly visible (Figure 7c) and the images clearly show that CPU2 coating has good wettability to the PA 6 fiber with no

Table I. Characteristic properties of PA 6, Ann PA, CPU2 and CPU2-PA6 fiber

\begin{tabular}{lcccccc}
\hline Sample & $\begin{array}{c}\mathrm{K} \\
\text { value }\end{array}$ & $\begin{array}{c}\text { Coating } \\
\text { thickness } \\
\mu \mathrm{m} \\
\text { (ave.) }\end{array}$ & $\begin{array}{c}\text { Density } \\
\mathrm{g} / \mathrm{cm}^{3}\end{array}$ & $\begin{array}{c}\text { Coating. } \\
\text { Weight } \\
\text { fraction } \\
(\%)\end{array}$ & $\begin{array}{c}\text { Coating } \\
\text { volume } \\
\text { fraction } \\
(\%)\end{array}$ & $\begin{array}{c}\text { Appearance/ } \\
\text { transparency }\end{array}$ \\
\hline PA 6 & - & - & 1.22 & - & - & High \\
Ann-PA6 & - & - & 1.22 & - & - & High \\
CPU2-PA6 & 2.05 & 40 & 1.23 & 20.3 & 20.4 & High \\
CPU2 & 2.05 & - & 1.13 & - & - & High \\
\hline
\end{tabular}

cracks or other irregularities observed on the CPU2 coating. Also, the CPU2-PA6 fibers showed good flexibility and external appearance. The hydrogen bonding interaction formed between the urethane group of CPU2 and amide group of PA 6 fiber plays a significant role in the formation of interface interaction region. Since the micro-cracks strongly affect the mechanical behavior of the PA 6 fibers, it is expected that interface interaction region enhanced the mechanical property by delaying the formation of micro-cracks.

\section{FT-IR Analysis}

FT-IR cross sectional scanning was conducted to find the interface interaction between the PA 6 fiber and the CPU2 thin film coating. Figure $2 \mathrm{a}$ shows the FT-IR cross sectional scanning spectra of the CPU2-PA6. The spectra were taken at three positions; they are the outer CPU2 coating, CPU2/PA 6 interface and inner PA 6 fiber core. The peak at $1708 \mathrm{~cm}^{-1}$ corresponds to the hydrogen bonded carbonyl stretching band and the peak at $1742 \mathrm{~cm}^{-1}$ corresponds to $v \mathrm{C}=\mathrm{O}$ free bond. Thus, the presence of CPU2 coating on the prepared samples was confirmed. The interface region comprises of CPU2 coating and the PA 6 fiber. The peak at $1739 \mathrm{~cm}^{-1}$ corresponds to the $v \mathrm{C}=\mathrm{O}$ free bond, the peaks at 1536 and $1601 \mathrm{~cm}^{-1}$ show the characteristic amide peaks of the PA 6 fiber. The peak at $1706 \mathrm{~cm}^{-1}$ represents $v \mathrm{C}=\mathrm{O} \mathrm{H}$-bonding, which confirmed the presence of strong hydrogen bonding interaction between the urethane group of CPU2 and amide group of PA 6 fiber. The amide groups at the surface of PA 6 fiber contribute to the hydrogen bonding interaction between the PA 6 and CPU2 coating. Thus an interface interaction region of $10 \mu \mathrm{m}$ was formed at the interface. The peaks at 1535 and $1601 \mathrm{~cm}^{-1}$ representing the characteristic amide II and amide I regions, confirmed the presence of PA 6 fiber at the inner core.

The structural changes of a crystal system were analyzed based on the FT-IR spectra of CPU2-PA6 fiber as shown in the range from $800-1150 \mathrm{~cm}^{-1}$ (Figure 2b). Polyamide 6 is a semi crystalline polymer, which has the stable $\alpha, \gamma$ and unstable $\beta$ crystalline forms. The hydrogen bonds are formed between the antiparallel chains in the $\alpha$ crystalline form and between the parallel chains in the $\gamma$ crystalline form. The important difference between these two structures is that the chain-axis 
repeat is $17.24 \AA$ in the $\alpha$ form due to the extended planar conformation and for $\gamma$ form it is $16.88 \AA$ due to the twisted helical transformation. The $\beta$ form is said to be the variant of $\gamma$ form in which the chains have a disordered conformation with no definite chirality. The chain-axis repeat of this phase is $16.7 \AA .{ }^{15}$ The two structures are interchangeable in such a way that the $\alpha$ crystalline form can be changed into the $\gamma$ crystalline form by means of treatment in the aqueous iodine and potassium iodide solution. The $\gamma$ crystalline form can be transformed into the $\alpha$ crystalline form through treatment with an aqueous phenol solution. ${ }^{16}$ During the fiber spinning, crystallization occurs from the amorphous phase to $\alpha$ form and from $\gamma$ to $\alpha$ crystalline transformations. During annealing, transformation occurs from the amorphous phase to the $\alpha$ crystalline form only. ${ }^{17}$ The peaks at 830,930 and $960 \mathrm{~cm}^{-1}$ show the characteristic $\alpha$ crystalline form (CO-NH in plane stretching). ${ }^{17,18}$ The absence of peak at $980 \mathrm{~cm}^{-1}$ indicates the absence of $\gamma$ crystalline form. ${ }^{17,18}$ Thus, it is conceivable that the PA 6 fibers used in the present study had only the $\alpha$ crystalline form. The peaks at 830,930 and $980 \mathrm{~cm}^{-1}$ showed a slight increase in intensity in the case of CPU2-PA6 fiber compared to the PA 6 fiber. This increase in intensity of the peak is due to the transformation that occurred from the amorphous phase to the $\alpha$ crystalline form.

\section{WAXD Analysis}

Figure 3 shows the WAXD profiles of PA6, Ann PA, CPU2PA6, and CPU2. The crystalline peaks of PA 6 are mainly composed of two peaks of $\alpha$ crystalline forms namely, $\alpha_{1}$ and $\alpha_{2}$. The $\alpha_{1}$ peak at $2 \theta=19.3^{\circ}$ is sensitive to the distance between hydrogen bonded chains inside the PA 6 lamellar sheets inside the fiber. The $\alpha_{2}$ peak at $2 \theta=22.6^{\circ}$ is sensitive to the separation distance between the PA 6 lamellar sheets. ${ }^{19,20}$ For CPU2, a shallow amorphous peak was observed at $20.2^{\circ}$. As seen clearly from Figure 3, it was found that the peak intensities, $\alpha_{1}$ and $\alpha_{2}$ of CPU2-PA6 samples showed an

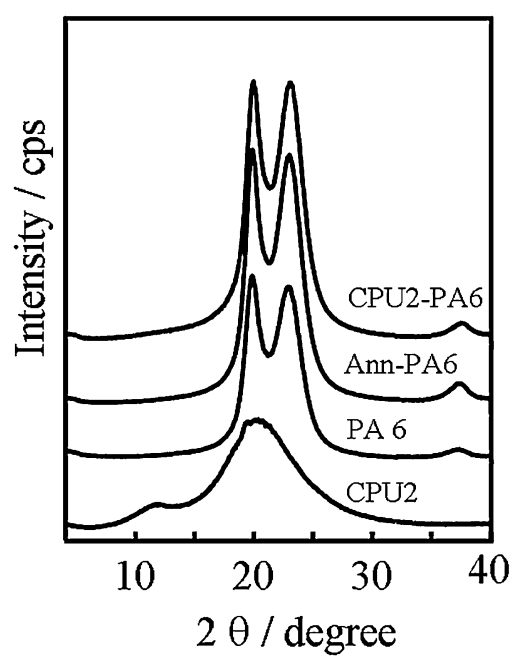

Figure 3. Wide angle X-ray diffraction profiles (equatorial scan) of CPU2, PA 6, Ann-PA6 and CPU2-PA6 samples.

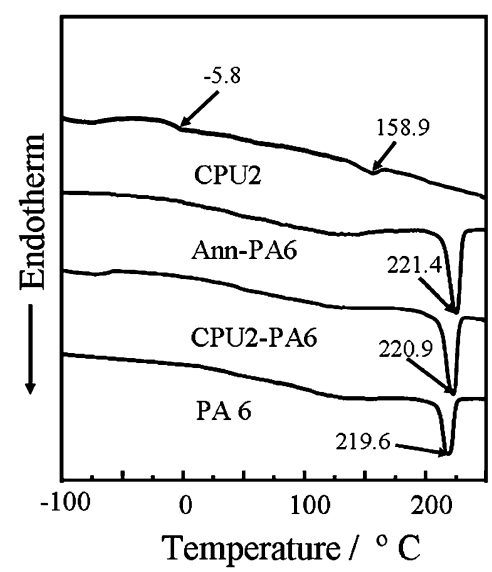

Figure 4. DSC thermograms of PA 6, Ann-PA6, CPU2-PA6 and CPU2 samples.

increase. This indicates that there was a rearrangement in the polyamide chain due to the CPU2 coating, resulting in the transformation from the amorphous phase to the $\alpha$ crystalline phase as discussed above.

\section{DSC and Thermo Viscoelastic Properties}

Figure 4 shows the DSC thermograms of the samples studied. The melting of the crystallized PA 6 chains was observed at around $220^{\circ} \mathrm{C}$ for PA 6, Ann PA and CPU2-PA6. On the contrary, the $T_{\mathrm{g}}$ of soft segment and melting point of hard segment domains were observed at $-5.8^{\circ} \mathrm{C}$ and $158.9^{\circ} \mathrm{C}$ for CPU2. Thus, the CPU2 coating had a clear microphase separation between the hard and soft segments. As stated above, $T_{\mathrm{m}}$ of the PA 6 showed no variation with CPU2 coating. In other words, polyurethane coatings have no significant effect on $T_{\mathrm{m}}$ of the polyamide 6 fibers. As seen in the thermograms, the crystallinity showed an increase in the case of CPU2-PA6 fibers compared to the uncoated ones.

The temperature dependence of storage modulus $\left(E^{\prime}\right)$ and the loss factor $(\tan \delta)$ of the samples is shown in Figure 5. The PA 6 showed three loss factor peaks named as $\alpha, \beta$ and $\gamma$ relaxation peaks, respectively. The $\alpha$-damping peak corresponds to the glass transition temperature, $T_{\mathrm{g}}\left(55^{\circ} \mathrm{C}\right)$. This peak occurs due to the rupture of hydrogen bonds between polymeric chains, which gives rise to the motion of the longer chain segments in the amorphous PA 6 lamellar planes. ${ }^{20}$ The transformation from the amorphous phase to $\alpha$-crystalline form occurs in this region. On the other hand, $\beta$-transition is attributed to the segmental motion that involves amide groups in the amorphous regions, which are not hydrogen bonded to other amides or to a nearby chain. The $\gamma$-transition is associated with the small-scale reorientational motion of the $\mathrm{CH}_{4}$ units in the amorphous region. ${ }^{20}$ The storage modulus showed a slight increase for the CPU2-PA6 samples. This may be due to the interface interaction and the crystalline rearrangement that occurred due to the CPU2 coating.

\section{Mechanical Properties}

Table II shows the mechanical properties of the samples 


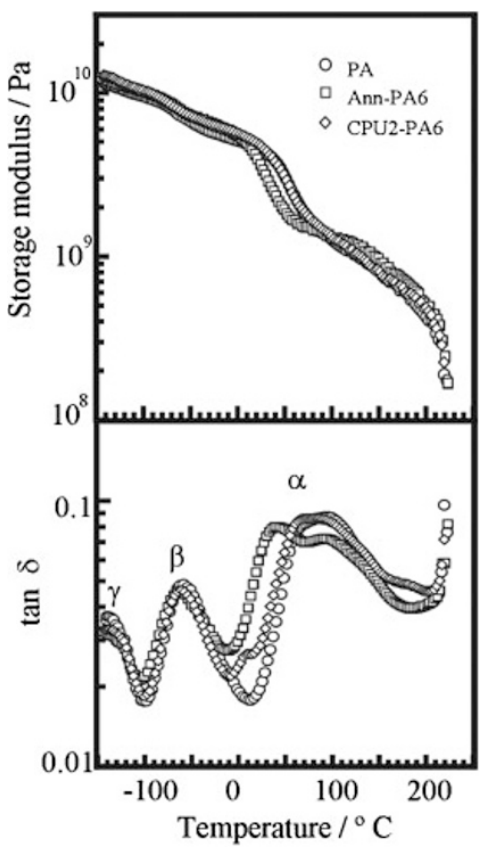

Figure 5. Temperature dependence of the storage modulus $\left(E^{\prime}\right)$ and loss modulus ( $\left.E^{\prime \prime}\right)$ of PA 6, Ann-PA6 and CPU2-PA6 samples.

Table II. Mechanical properties of PA 6, Ann PA, CPU2 and CPU2-PA6 fiber

\begin{tabular}{lccccccc}
\hline Sample & $\mathrm{K}^{(\mathrm{a})}$ & $\begin{array}{c}\sigma_{\mathrm{b}}{ }^{(\mathrm{b})} \\
(\mathrm{MPa})\end{array}$ & $\boldsymbol{\varepsilon}_{\mathrm{b}}{ }^{(\mathrm{c})}$ & $\begin{array}{c}E^{(\mathrm{d})} \\
(\mathrm{GPa})\end{array}$ & $\begin{array}{c}T_{\mathrm{g}} \\
{ }^{\circ} \mathrm{C}\end{array}$ & $\begin{array}{c}T_{\mathrm{m}} \\
{ }^{\circ} \mathrm{C}\end{array}$ & $\begin{array}{c}\Delta H \\
(\mathrm{~J} / \mathrm{g})\end{array}$ \\
\hline PA 6 & - & 650.5 & 0.33 & 2.85 & 55.1 & 219.6 & 48.6 \\
Ann-PA6 & - & 681.2 & 0.35 & 3.22 & 51.2 & 221.4 & 54.4 \\
CPU2-PA6 & 2.05 & 769.6 & 0.67 & 3.55 & 54.2 & 220.9 & 61.4 \\
CPU2 & 2.05 & 26.6 & 4.0 & 26.1 & -5.8 & 158.9 & 4.4 \\
& & & & $(\mathrm{MPa})$ & $\mathrm{SS}$ & $\mathrm{HS}$ & \\
\hline
\end{tabular}

(a): $\mathrm{K}=[\mathrm{NCO}] /[\mathrm{OH}],(\mathrm{b})$ : Tensile strength, (c): Strain at break, (d): Young's modulus, SS and HS represents hard segment and soft segment respectively.

studied. Figure 6 shows the stress strain properties of CPU2 coated and uncoated PA 6 fibers. The strength and the elongation at break increased with the CPU2 coating. Also, the Young's modulus too increased with the coating. In the rapid process of fiber manufacturing, spinning and rapid cooling, there is an incomplete of growth of polyamide lamellar structures. This results in the disordered regions all along the PA 6 fibers. $^{21}$ During annealing there will be a rearrangement in the lamellar structures, results in the increase of elongation of the annealed PA 6 fiber samples. ${ }^{17,21}$ But the CPU2-PA6 sample showed a much greater mechanical performance compared to the annealed PA 6 samples.

When the PA 6 fiber undergoes tensile stress, micro-cracks are formed on the surface of fibers. In the case of CPU2-PA6 fibers the thin film coating delayed the formation of microcracks and subsequently the thin film coating entered these micro-cracks when they were formed while under mechanical stress. This contributed to the increase of the strength and elongation of the CPU2-PA6 fibers. Figure 7a shows the surface and cross sectional view of the PA 6 fiber at break.

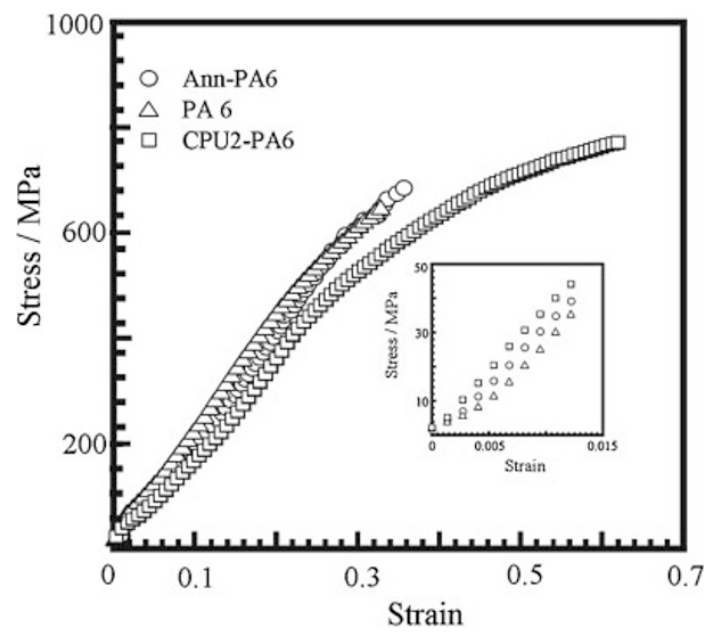

Figure 6. Stress-strain curves of PA 6, Ann-PA6 and CPU2-PA6 samples.
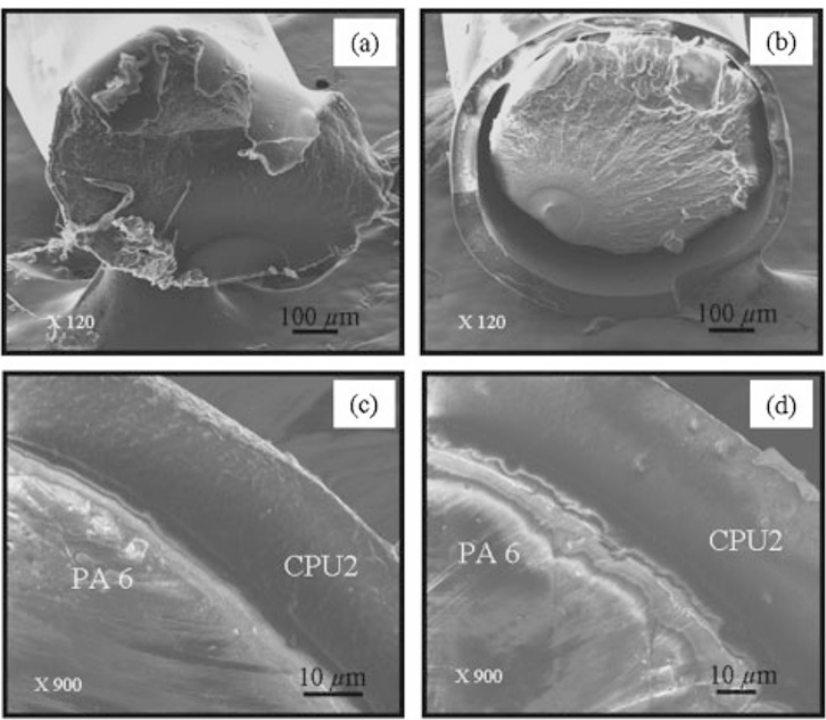

Figure 7. FE-SEM images (a) view of PA 6 fiber at break, (b) view of CPU2PA6 fiber at break, (c) interface region of CPU2-PA6, (d) interface region of CPU2-PA6 fiber after tensile test.

There is a thin layer of amorphous region on the surface of the PA 6 fiber. The surface layer of the PA 6 fiber was dragged behind the inner region during the elongation process, so the resulted break was a plastic-type break. When the PA 6 fiber is dip coated with CPU2, the amorphous region on the surface of the fiber interacts strongly with the coating. Under mechanical tension, the CPU2 thin film coating delayed the formation of micro-cracks on the surface of the PA 6 fibers. Eventually, the interface interaction region stiffens and the CPU2 coating enters into the micro-cracks resulting in a metallic-type break (Figure $7 \mathrm{~b}$ ). The stress concentration points are observed on both the CPU2-PA6 fibers and PA 6 fibers after tensile test. Figure $7 d$ shows cross sectional view of fiber which have undergone mechanical tension equivalent to $90 \%$ of the break load. The micro-cracks are clearly visible and the CPU2 coating has entered into these cracks during the deformation of 


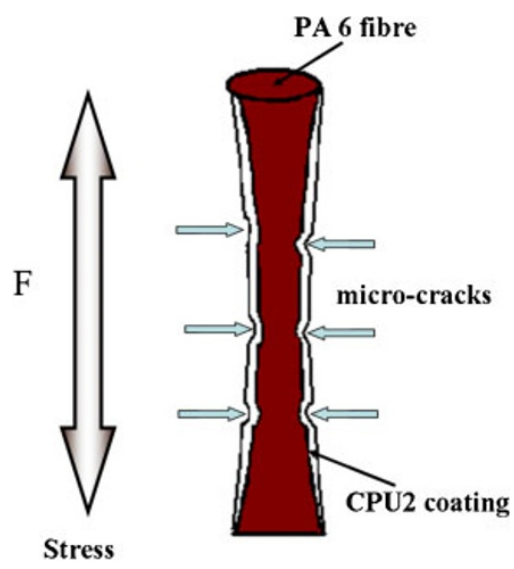

Figure 8. Formation of micro-cracks and the entry of CPU2 into the PA 6 fiber when under mechanical tension.

the fiber. The width of the interface interaction got increased from $10 \mu \mathrm{m}$ to $20 \mu \mathrm{m}$. Figure 8 shows schematically how the micro-cracks are formed and the entry of CPU2 into it when under mechanical tension.

Thus, the increase of the strength and elongation of the CPU2-PA6 fibers can be attributed to three factors. They are (1) the increase in crystallinity due the transformations that occurred in the crystalline regions due to the CPU2 coating, (2) the formation of $1 \mathrm{f}$ the interface interaction region, (3) the role played by the interface interaction region along with the microcracks when the fiber was under mechanical load.

\section{CPU2 Coating on PA 6 Film and Adhesion Analysis}

The CPU2-PA6 films were prepared to find the adhesion of CPU2 coating with PA 6. Table III shows the adhesion properties of the CPU2-PA6 films. The strength and elongation of CPU2-PA6 films improved with coating when compared to the annealed PA 6 films. The adhesions tests conducted were Tpeel, single lap shear and peeling tests. The tensile strength of the CPU2-PA6 film was twice as large as that of the PA 6 film and the CPU2 coating showed good adhesion with PA 6 films. The adhesion strength was nearly equal for all the types of adhesion tests conducted.

Table III. Adhesion properties of CPU2-PA6 films

\begin{tabular}{lccccc}
\hline \multicolumn{1}{c}{ Index } & $\begin{array}{c}\text { PA 6 film } \\
\text { thickness } \\
\mu \text { m (ave.) }\end{array}$ & $\begin{array}{c}\text { Coating } \\
\text { thickness } \\
\mu \text { m (ave.) }\end{array}$ & $\begin{array}{c}\text { Max } \\
\text { Tensile } \\
\text { strength } \\
(\mathrm{MPa})\end{array}$ & $\begin{array}{c}\text { Strain } \\
\text { at } \\
\text { break }\end{array}$ & $\begin{array}{c}\text { Young's } \\
\text { Modulus } \\
(\mathrm{GPa})\end{array}$ \\
\hline PA 6 film & 200 & - & 230 & 1.6 & 0.71 \\
Ann-PA6 film & 200 & - & 328 & 0.7 & 0.80 \\
CPU2-PA6 film & 200 & 50 & 442 & 1.1 & 0.82 \\
$\begin{array}{l}\text { Single lap shear } \\
\text { CPU2 + PA 6 film }\end{array}$ & 200 & 50 & 350 & - & - \\
$\begin{array}{c}\text { Peeling strength } \\
\text { CPU2 + PA 6 film }\end{array}$ & 200 & $150^{*}$ & 440 & - & - \\
$\begin{array}{c}\text { T-Peel strength } \\
\text { CPU2 + PA 6 film }\end{array}$ & 200 & 50 & 320 & - & - \\
\hline
\end{tabular}

${ }^{*}$ CPU2 film is a very soft material, so the film thickness increased to do the peeling test.

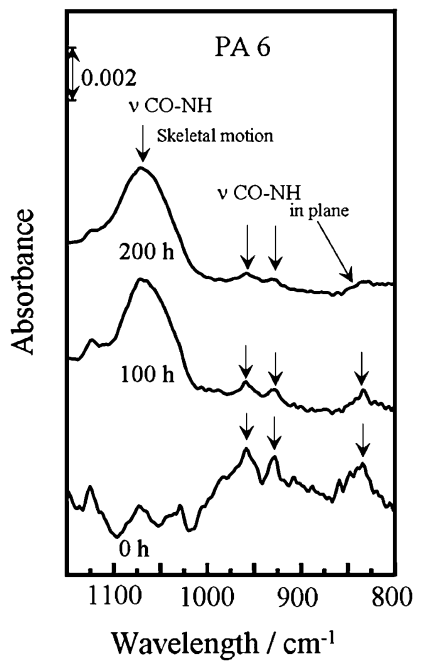

Figure 9. Structural changes in the PA 6 fibers exposed to weathering tests.

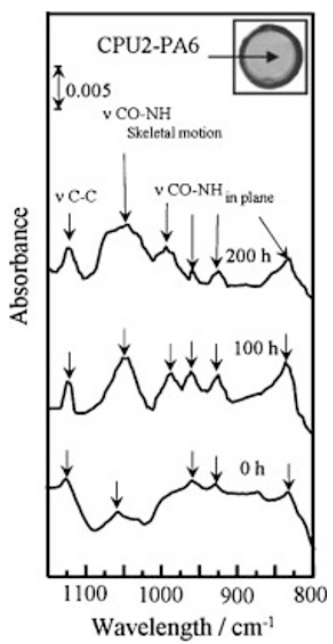

Figure 10. Structural changes in the CPU2-PA6 fibers exposed to weathering tests.

\section{Weathering Resistance of CPU2-PA6 Fibers}

Weathering tests was conducted to check the performance level of the CPU2-PA6 fibers for the out door applications. Figure 9 shows the FT-IR spectra of the PA 6 fibers for various weathering intervals. The peaks at $830,930,960 \mathrm{~cm}^{-1}$ corresponding to the $\alpha$-crystalline form (CO-NH in plane stretching) showed a sharp decrease in intensity with the weathering tests, which indicates that the crystallinity of PA 6 fiber got decreased with the exposure. ${ }^{17}$ This was due to the destruction of $\mathrm{C}=\mathrm{O}$ bonds by $\mathrm{UV}$ radiation from the Xe lamp and thereby the amide I and amide II bands were affected, resulting in the weakening of the amide linkage. Figure 10 shows the FT-IR spectra of the CPU2-PA6 fibers after weathering tests. The emergence of $\gamma$ crystalline peak was observed along with the $\alpha$-crystalline peaks. A new peak at $980 \mathrm{~cm}^{-1}$ is assigned to the $\gamma$ crystalline form, was clearly observed in the range $0-50 \mathrm{~h}$ of weathering exposure. Thus, a 


\begin{tabular}{|c|c|c|c|c|}
\hline Sample & $\begin{array}{l}\text { UV irradiation } \\
\text { time } \\
\text { (h) }\end{array}$ & $\begin{array}{c}\sigma_{\mathrm{b}}^{(\mathrm{a})} \\
(\mathrm{MPa})\end{array}$ & $\varepsilon_{\mathrm{b}}^{(\mathrm{b})}$ & $\begin{array}{c}\mathrm{E}^{(\mathrm{c})} \\
(\mathrm{GPa})\end{array}$ \\
\hline \multirow{5}{*}{ PA 6} & 0 & 646 & 0.33 & 2.85 \\
\hline & 50 & 642 & 0.30 & 2.83 \\
\hline & 100 & 565 & 0.27 & 2.12 \\
\hline & 150 & 367 & 0.18 & 1.82 \\
\hline & 200 & 316 & 0.17 & 1.54 \\
\hline \multirow{5}{*}{ CPU2-PA6 } & 0 & 769 & 0.67 & 3.55 \\
\hline & 50 & 876 & 0.60 & 3.64 \\
\hline & 100 & 793 & 0.47 & 3.58 \\
\hline & 150 & 754 & 0.34 & 3.42 \\
\hline & 200 & 686 & 0.28 & 3.33 \\
\hline
\end{tabular}

(a): Tensile strength, (b): Strain at break, (c): Young's modulus.

crystalline transformation from the $\alpha$ to $\gamma$ crystalline form, was induced by UV irradiation from the weatherometer. Similar type of crystalline transformation was reported earlier when the PA 6 fibers were treated with aqueous iodine or potassium iodide or chlorine solution. ${ }^{16}$ The presence of ionic groups or radicals is very much necessary for $\alpha$ to $\gamma$ crystalline transformation. But, in the case of CPU2 coating the possibility of ionic radical or groups present in the coating is almost nil. The UV irradiation softened the CPU2 coating and thereby the changes had occurred in the elastomeric chains in the CPU2 coating, which in turn influenced the PA 6 lamellar structures causing the crystalline transformation. The UV assisted crystalline transformation in PA 6 fibers has not been reported yet. The peak at $1070 \mathrm{~cm}^{-1}$ (CO-NH in skeletal motion) is often taken as indicator of $\mathrm{C}=\mathrm{O}$ bond breakage due to the $\mathrm{UV}$ irradiation. Both PA 6 and CPU2-PA6 showed an increase in intensity of this peak, which implies that there was a degradation of CO-NH bonding. Also, the peaks at 830, 930 and $960 \mathrm{~cm}^{-1}$, representing $\alpha$ crystalline form showed a slight increase. This might have been due to the black panel temperature $\left(65^{\circ} \mathrm{C}\right)$ inside the weatherometer, which induced a transformation from the amorphous phase to $\alpha$-crystalline phase due to the heating effect.

Table IV shows the mechanical properties of the UV irradiated PA 6 fibers and CPU2-PA6 samples. The strength of the PA 6 fiber got decreased to below 50\% compared to the non irradiated ones. The $\mathrm{C}=\mathrm{O}$ bonds were easily attacked and destructed by UV rays resulting in the weakening of the amide linkage of PA 6 fibers. So there will be a decrease in the overall crystallinity of irradiated PA 6 fibers. Figure 11 shows the mechanical properties of the CPU2-PA6 samples after the weathering tests. There was an increase in the strength of CPU2-PA6 sample in the range $0-50 \mathrm{~h}$ of exposed to weathering. Also, it was clearly seen that after $200 \mathrm{~h}$ of exposure to weathering, there was no much decrease in the mechanical strength compared to the non exposed CPU2-PA6 samples. Thus, the CPU2 coating is a good protective coating for the PA 6 fibers. One interesting fact is that when PA 6 or CPU2 films are exposed to weathering tests for $200 \mathrm{~h}$, both are degraded beyond use. The PA 6 fibers when coated with CPU2 thin

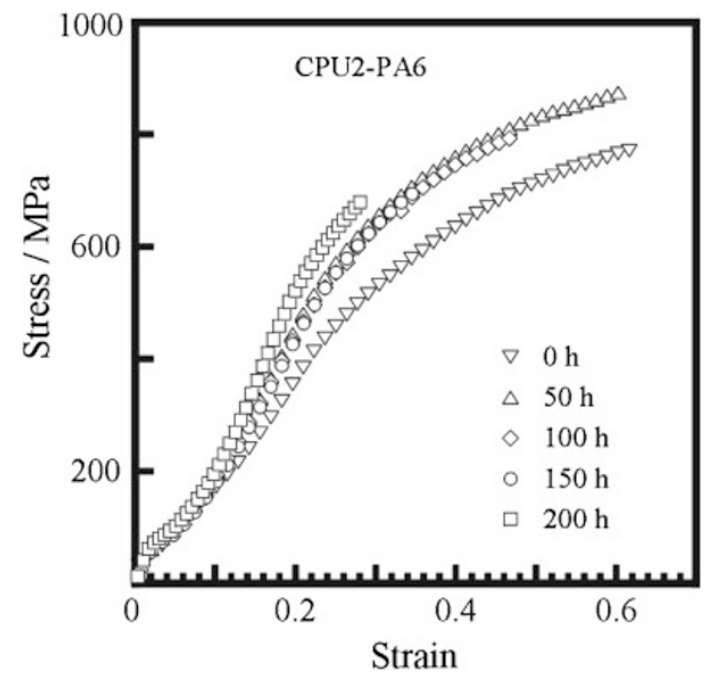

Figure 11. Stress-strain curves of the CPU2-PA6 samples after weathering tests.

films, the mechanical strength and weathering resistance got improved drastically.

\section{CONCLUSION}

The polycarbonate based thermoplastic polyurethane (CPU2) thin film coating improved the performance of PA 6 fibers. The coating didn't sacrifice the appearance or the flexibility of the fiber but it improved the physical properties as well. Also, the CPU2 coating provided good weathering resistance and adhesion property with PA 6 fibers. The strength as well as the elongation improved with the CPU2 coating. The changes that occurred in PA 6 with the CPU2 thin film coating are the transformation from the amorphous phase to $\alpha$ crystalline form, the formation of interface interaction region and the interface stiffening along with micro-cracks when the fiber was under mechanical tension. When the CPU2-PA6 was exposed to weathering tests, the strength again increased due to the $\alpha$ to $\gamma$ crystalline form transformations. Thus, the CPU2 thin film coating proved to be a better coating for PA 6 fibers in all aspects. One shot dip coating method of CPU2 coating on PA 6 fibers is very convenient for various industrial applications compared to the traditional method of blending various materials with PA 6 for the better performance.

Acknowledgment. The authors would like to thank Dr. Suguru Motokucho for the assistance in research discussions during the study.

Received: November 6, 2008

Accepted: January 8, 2009

Published: February 18, 2009

\section{REFERENCES}

1. M. Palabiyik and S. Bahadur, Wear, 246, 149 (2000).

2. N. S. Murthy, S. A. Curran, S. M. Aharoni, and H. Minor, 
Macromolecules, 24, 3215 (1991).

3. M. Xanthos, Polym. Eng. Sci., 28, 1392 (1988).

4. Z. S. Petrovic and J. Fergusion, Prog. Polym. Sci., 16, 695 (1991).

5. M. Furukawa, M. Komiyama, and T. Yokoyama, Angew. Makromol. Chem., 240, 205 (1996).

6. R. Elluech, A. Elluech, B. Salah, and H. Zahouani, Mater. Des., 28, 824 (2007).

7. M. Furukawa, Y. Hamada, and K. Kojio, J. Polym. Sci., Part B: Polym. Phys., 41, 2355 (2003).

8. K. Kojio, T. Fukumaru, and M. Furukawa, Macromolecules, 37, 3287 (2004).

9. K. Dijkstra, J. T. Laak, and R. J. Gaymans, Polymer, 35, 315 (1994).

10. B. Majumdar, H. Keskula, and D. R. Paul, Polymer, 35, 5453 (1994).

11. A. Genovese and R. Shanks, Comput. Theor. Polym. Sci., 11, 57 (2001).

12. J. T. Haponiuk, J. Therm. Anal., 60, 45 (2000).
13. X. Li, M. Chen, Y. Huang, and G. Cong, Polym. J., 29, 975 (1997).

14. K. Kojio, Y. Nonaka, T. Masubuchi, and M. Furukawa, J. Polym. Sci., Part B: Polym. Phys., 42, 4448 (2004).

15. "Nylon Plastics Handbook," M. I. Kohan, ed., New York, 1995. p. 107.

16. N. Vasanthan and D. R. Salem, J. Polym. Sci., Part B: Polym. Phys., 38, 516 (2000).

17. G. Rotter and H. Ishida, J. Polym. Sci., Part B: Polym. Phys., 30, 489 (1992).

18. J. Maillo, P. Pages, E. Vallejo, T. Lacorte, and J. Gacen, Eur. Polym. J., 41, 753 (2005).

19. Q. Wu, X. Liu, and L. Berglund, Polymer, 43, 2445 (2002).

20. L. P. Penel-Pienon, C. Depecker, R. Seguela, and J. M. Lefebvre, J. Polym. Sci., Part B: Polym. Phys., 39, 484 (2001).

21. "Polymer Science, (A Material Science Handbook)," A. D. Jekins, Ed., Vol. 1, North-Holland Publishing Company, London, 1972. 